\title{
Nutrient intake, dietary patterns, and anthropometric variables of children with ADHD in comparison to healthy controls: a case-control study
}

\author{
Habibeh Salvat ${ }^{1}$, Mehriar Nader Mohammadi ${ }^{1}$, Parviz Molavi ${ }^{*}$, Seyed Ali Mostafavi ${ }^{2}$, Reza Rostami ${ }^{3}$ and \\ Mohammad Ali Salehinejad ${ }^{4^{*}}$
}

\begin{abstract}
Background: Poor health behaviors and variables are recently more documented in attention-deficit hyperactivity disorder (ADHD) lifestyle which might be relevant to the pathophysiology of this disorder. The objective of this casecontrol study was to assess the nutrient intake, dietary patterns, and anthropometric variables in children with ADHD compared to normal peers.

Method: One hundred children diagnosed with ADHD were included and compared to 100 healthy, sex-matched normal children as the control group. Anthropometric indices, macronutrients, and micronutrients were measured and compared in both groups.

Results: ADHD children were significantly consuming more simple sugars, tea, ready-made meals but less protein, vitamin B1, vitamin B2, vitamin C, zinc and calcium compared to the control group. The body mass index (BMI) and waist circumference of children with ADHD were significantly higher and were related to the severity and type of the disease.
\end{abstract}

Conclusion: Unhealthy eating behavior is more frequent in children with ADHD, compared to normal children which might warrant lifestyle intervention in this disorder.

Keywords: Attention-Deficit Hyperactivity Disorder (ADHD), lifestyle, Anthropometry, Nutrition

\section{Background}

Attention-deficit and Hyperactivity Disorder (ADHD) is a common neurodevelopmental disorder of childhood and adolescence [1] marked with core symptoms of inattention and hyperactivity [2] and cognitive dysfunctions (e.g., working memory, inhibition control)

\footnotetext{
*Correspondence: p.molavi@yahoo.com; salehinejad@ifado.de

${ }^{1}$ Department of Psychiatry, Fatemi Hospital, School of Medicine, Ardabil University of Medical Sciences, Ardabil, Iran

${ }^{4}$ Department of Psychology and Neurosciences, Leibniz Research Centre for Working Environment and Human Factors, Dortmund, Germany Full list of author information is available at the end of the article
}

$[3,4]$ with a well-documented underlying pathophysiology in the brain [5]. There is a consensus that the etiology of ADHD is heterogeneous and results from a complex interaction of pathophysiological and neurochemical systems with genetic phenotype. Other factors that contribute to the onset or sustainability of ADHD symptoms include psychosocial, environmental, and dietary factors [6-8]. The symptoms of inattention, impulsivity, and poor planning are suggested to contribute to poor health behaviors in ADHD patients [9] Considering such diverse etiological factors, alternative or nonmedical treatments have been also proposed 
for the treatment or alleviation of ADHD symptoms including several kinds of dietary interventions [10]. In this line, however, there is still an urgent need for studies investigating dietary-related factors between ADHD children and their typically developing peers.

One factor related to dietary behavior is anthropometric indices. The word anthropometry consists of two parts: the anthropus means the human and the metric means measuring and is referred to as the measurement of human physical indices. One of the aims of anthropometric measurements is to examine the human body size and shape. In the developing population including children and adolescents, anthropometric measurements are applied as variables of growth and development [11]. Other anthropometric variables including body weight, height, body mass index (BMI), skinfold thickness, peripheral measurements and measuring fat mass, and muscle mass are usually used for nutritional evaluations [12].

Some of these anthropometric variables are investigated in children with ADHD. A study in this respect investigated the changes in body and hormone levels in children with ADHD and found that several variables are either lower or higher in children with ADHD when compared to typically-developing controls [13, 14]. In another study, several differences in nutritional patterns were observed between children with ADHD and healthy controls. These differences were "not eating" breakfast, having a history of food allergies which contributed to ADHD symptoms severity, and higher intake of daily sugar in children with more severe ADHD symptoms [15]. Another related study reported a significantly lower weight and height of children with ADHD in comparison with their peers without ADHD [16]. In contrast, another study investigated obesity and overweight of ADHD children and found that 10-17 years old boys and 10-17 years old girls with ADHD were significantly overweight than those in the control group [17]. ADHD as a potential risk factor for obesity and overweight is supported in another study that assessed the prevalence of obesity and overweight in children with ADHD [18].

The association of dietary behavior and ADHD symptoms is important for the well-being, general health, and development of children with ADHD, however, a limited number of studies exist in this respect. Moreover, although the above-mentioned studies provide some insight about nutrients and anthropometric variables in ADHD, no comprehensive investigation of variables is available. Finally, the mixed results from previous studies warrant further investigation in carefully-controlled case studies. Accordingly in the present study, we aimed to assess the dietary patterns, nutrient intake, and anthropometric variables in ADHD children as compared with normal children. Additionally, we assessed the anthropometric variables with regard to ADHD subtype and severity of symptoms.

\section{Methods \\ Study design population}

This study adopted a case-control design and performed on children aged 5-13 years old with and without ADHD. Sample size was determined based on previous similar works and using the Cochran formula and 200 children, including 100 children with ADHD (case group) and 100 typically developing controls (control group) were recruited. To reduce the confounding factors, two groups were matched for age and sex. Considering that the sample was selected in Ardabil, all the children present in the study were Azeri and of the same race. Inclusion criteria for the ADHD group were (1) meeting Diagnostic and Statistical Manual of Mental Disorders criteria (DSM-5) [2] for ADHD by consensus of the two experienced child psychiatrists, (2) no history of confounding medical, neurological, and psychiatric conditions, (3) and parent's scoring on the Conners Rating Scale [19]. Typically developing controls underwent the same evaluation and diagnostic procedure.

\section{Ethics}

All ethical requirements according to the declaration of Helsinki were met. The study protocol was described to parents and their children. We obtained the written informed consent form parents and oral assent from children before participation in the study. Ethical approval was obtained from the ethics committee review board of the Ardabil University of Medical Sciences (ethics code: IR.ARUMS.REC.1395.81).

\section{Study procedure}

Participants in the ADHD group were selected from the patients referred to the Fatemi Hospital of the correspondent university and healthy controls were age and sex-matched from kindergartens and schools during the year 2018. In both groups, children were screened for ADHD by a professional child psychiatrist according to the clinical interview based on the DSM-5 diagnostic criteria. The healthy control group was also interviewed for ruling out ADHD and other neurodevelopmental disorders. The severity of the disorder was furthermore assessed by the Conners questionnaire (parent form) [19]. Then dietary intake and anthropometric variables were assessed in both groups.

\section{Anthropometric assessment}

In this study, anthropometric variableswere measured by a trained physician. Anthropometric parameters 
were measured in the standard positions. Bodyweight was measured on a calibrated digital scale, to the nearest $0.1 \mathrm{Kg}$, for this purpose the subjects wore minimal clothes without shoes. Height was measured by an unstretchable tape on a wall with a straight body position to the nearest $0.1 \mathrm{~cm}$. Waist and arm circumferences were measured by an un-stretchable tape to the nearest $0.1 \mathrm{~cm}$. Body mass index (BMI) was calculated by dividing weight $(\mathrm{kg})$ to height squared $(\mathrm{m} 2)$.

\section{Dietary assessment}

The children's nutritional information was collected by the Food Frequency Questionnaires (FFQ) [20]. The guideline for food portion sizes was delivered to parents and they were instructed to fill the FFQ for their children. The parents were asked to sort their children's average frequency consumption of each food item during the past year according to food portion sizes. Furthermore, a three-day food record was collected from participants. The parents should record all foods and beverages consumed by their children over three randomly selected days (two regular days and one weekend). The gathered data of dietary intake were analyzed by N4 software.

\section{Statistical analysis}

Data analysis was conducted using the SPSS-21 software package. Descriptive statistics including mean and standard deviation were used for data overview and to compare groups (ADHD vs control) in outcome measures (waist circumference, BMI, nutrients intake), independent Student's t-test was performed. The effect of ADHD subtype (3 values) and symptom severity on each anthropometric variables was also investigated using the univariate analysis of variance (ANOVA). The assumptions of homogeneity of variances and normal distribution were examined with Levene's test for homogeneity of variances and Shapiro-Wilk test of normality respectively.

\section{Results}

\section{Data overview}

The mean age of the ADHD children in the case group was $8.33 \pm 2.10$ years and the mean age of the control group was $8.26 \pm 2.00$ years. $72 \%$ of both groups were boys and the rest were girls. There was no significant difference between the groups in these demographic variables. Demographic information and the mean and standard deviation of age, weight, height, BMI, and other anthropometric variables are summarized in Table 1.

\section{Anthropometric variables}

In the case group, 28 children were diagnosed with predominantly hyperactive/impulsive type, 11 children with the predominantly inattentive type and 61 children were diagnosed with the combined type of ADHD. Also, in this

Table 1 Comparison of different parameters of children in the case and control groups

\begin{tabular}{|c|c|c|c|c|}
\hline General category & Parameter & Case group & Control group & Group $P$-value \\
\hline \multirow[t]{3}{*}{ Age (Year) } & Mean \pm SD & $8.33 \pm 2.08$ & $8.26 \pm 2.08$ & NS \\
\hline & Min & 5 & 5 & \\
\hline & Max & 13 & 13 & \\
\hline \multirow[t]{2}{*}{ Sex } & Male & 72 (72\%) & 72 (72\%) & NS \\
\hline & female & $28(28 \%)$ & $28(28 \%)$ & \\
\hline \multirow[t]{3}{*}{ Weight (kg) } & Mean & $25.69 \pm 5.96$ & $25.05 \pm 6.60$ & NS \\
\hline & Min & 14 & 11.50 & \\
\hline & Max & 42.5 & 48.50 & \\
\hline \multirow[t]{3}{*}{ Height (cm) } & Mean & $122.68 \pm 12.07$ & $123.35 \pm 12.43$ & NS \\
\hline & Min & 92 & 97 & \\
\hline & Max & 152 & 151 & \\
\hline \multirow[t]{3}{*}{ BMI (kg/Sq. M) } & Mean & $16.99 \pm 2.17$ & $16.16 \pm 1.90$ & $0.012^{*}$ \\
\hline & Min & 13.20 & 11.39 & \\
\hline & Max & 28.10 & 26.04 & \\
\hline \multirow{3}{*}{$\begin{array}{l}\text { Waist } \\
\text { Circumference (cm) }\end{array}$} & Mean & $60.96 \pm 8.88$ & $58.38 \pm 8.69$ & $0.039^{*}$ \\
\hline & Min & 13.2 & 41 & \\
\hline & Max & 28.1 & 78 & \\
\hline \multirow{3}{*}{$\begin{array}{l}\text { Arm } \\
\text { Circumference }(\mathrm{cm})\end{array}$} & Mean & $22.61 \pm 4.51$ & $21.51 \pm 4.56$ & NS \\
\hline & Min & 13 & 12.50 & \\
\hline & Max & 40 & 34.00 & \\
\hline
\end{tabular}

NS: Not significant; * significant at the $p<0.05$ 
group according to conners score $49 \%$ had mild, $37 \%$ had moderate and $14 \%$ had severe ADHD symptoms. Table 2 summarized the anthropometric variablesin the children with ADHD subgrouped by type and severity of disease compared with the control group. There was a significant difference between ADHD children and their controls in the mean BMI $(p=0.012)$ and Waist Circumference $(p=0.039)$ (Table 1). The results of ANOVA showed a significant main effect of ADHD type on the BMI and mean waist circumference (Table 2). Post hoc analysis showed a significantly higher mean BMI in the inattentive subtype compared to the hyperactive type. Similarly,

Table 2 Anthropometric and type and severity of disease of ADHD in comparison with the control group

\begin{tabular}{|c|c|c|c|c|c|c|c|c|}
\hline General group & $\begin{array}{l}\text { Type and severity of } \\
\text { disorder }\end{array}$ & parameters & number & Mean & $\begin{array}{l}\text { Standard } \\
\text { deviation }\end{array}$ & $\mathbf{F}$ & $p$-values & Pairwise comparisons \\
\hline \multirow[t]{8}{*}{ Mean weight (kg) } & \multirow[t]{4}{*}{ Type of Disorder } & Control group & 100 & 25.05 & 6.60 & \multirow[t]{4}{*}{1.342} & \multirow[t]{4}{*}{0.262} & \multirow[t]{4}{*}{ na } \\
\hline & & Mostly hyperactive & 28 & 24.80 & 6.25 & & & \\
\hline & & Mostly attention deficit & 11 & 28.90 & 6.80 & & & \\
\hline & & Combined & 61 & 25.51 & 5.58 & & & \\
\hline & \multirow[t]{4}{*}{ The severity of Disorder } & Control group & 100 & 25.05 & 6.60 & \multirow[t]{4}{*}{0.731} & \multirow[t]{4}{*}{0.535} & \multirow[t]{4}{*}{ na } \\
\hline & & mild & 49 & 25.63 & 6.55 & & & \\
\hline & & moderate & 37 & 26.44 & 5.67 & & & \\
\hline & & severe & 14 & 23.89 & 4.24 & & & \\
\hline \multirow[t]{8}{*}{ Mean height (cm) } & \multirow[t]{4}{*}{ Type of Disorder } & Control group & 100 & 123.35 & 12.43 & \multirow[t]{4}{*}{0.827} & \multirow[t]{4}{*}{0.480} & \multirow[t]{4}{*}{ na } \\
\hline & & Mostly hyperactive & 28 & 122.00 & 12.67 & & & \\
\hline & & Mostly attention deficit & 11 & 128.00 & 10.16 & & & \\
\hline & & Combined & 61 & 122.03 & 12.04 & & & \\
\hline & \multirow[t]{4}{*}{ The severity of Disorder } & Control group & 100 & 123.35 & 12.43 & \multirow[t]{4}{*}{1.514} & \multirow[t]{4}{*}{0.212} & \multirow[t]{4}{*}{ na } \\
\hline & & mild & 49 & 121.42 & 13.19 & & & \\
\hline & & moderate & 37 & 125.81 & 11.00 & & & \\
\hline & & severe & 14 & 118.78 & 9.05 & & & \\
\hline \multirow[t]{8}{*}{ Mean BMI } & \multirow[t]{4}{*}{ Type of Disorder } & Control group & 100 & 16.16 & 1.90 & \multirow[t]{4}{*}{2.998} & \multirow[t]{4}{*}{$0.032^{*}$} & na \\
\hline & & Mostly hyperactive & 28 & 16.38 & 1.28 & & & \\
\hline & & Mostly attention deficit & 11 & 17.35 & 1.80 & & & $A D>H D$ \\
\hline & & Combined & 61 & 17.04 & 2.52 & & & na \\
\hline & \multirow[t]{4}{*}{ The severity of Disorder } & Control group & 100 & 16.16 & 1.90 & \multirow[t]{4}{*}{2.990} & $0.032^{*}$ & \\
\hline & & mild & 49 & 17.20 & 2.82 & & & mild $>$ control, moderate \\
\hline & & moderate & 37 & 16.49 & 1.18 & & & na \\
\hline & & severe & 14 & 16.84 & 1.38 & & & \\
\hline Mean waist circumfer- & Type of Disorder & Control group & 100 & 803.82 & 96.73 & 3.144 & $0.016^{*}$ & na \\
\hline ence $(\mathrm{cm})$ & & Mostly hyperactive & 28 & 734.46 & 75.77 & & & \\
\hline & & Mostly attention deficit & 11 & 804.09 & 82.69 & & & \\
\hline & & Combined & 61 & 780.00 & 139.79 & & & $\mathrm{AD} / \mathrm{HD}>\mathrm{HD}$ \\
\hline & The severity of disorder & Control group & 100 & 803.82 & 96.73 & 1.670 & 0.175 & na \\
\hline & & mild & 49 & 764.89 & 145.49 & & & \\
\hline & & moderate & 37 & 777.02 & 96.64 & & & \\
\hline & & severe & 14 & 768.57 & 85.40 & & & \\
\hline Mean arm circumfer- & Type of disorder & Control group & 100 & 21.51 & 4.55 & 2.341 & 0.075 & na \\
\hline ence $(\mathrm{cm})$ & & Mostly hyperactive & 28 & 21.83 & 4.46 & & & \\
\hline & & Mostly attention deficit & 11 & 25.045 & 4.17 & & & \\
\hline & & Combined & 61 & 22.53 & 4.50 & & & \\
\hline & The severity of disorder & Control group & 100 & 21.51 & 4.56 & 1.311 & 0.272 & na \\
\hline & & mild & 49 & 23.06 & 4.67 & & & \\
\hline & & moderate & 37 & 22.28 & 4.58 & & & \\
\hline & & severe & 14 & 21.92 & 3.80 & & & \\
\hline
\end{tabular}


the inattentive subtype had a significantly larger mean waist circumference compared to both hyperactive and combined subtypes.

\section{Dietary pattern, micro-and micronutrients}

Table 3 and Fig. 1 compares the dietary consumption of macronutrients and micronutrients as well as some dietary habits between the case and control groups. Table 3 indicates that the children in the ADHD group significantly consume more simple sugars $(p=0.007)$, tea $(p=0.006)$, and Ready-made meals $(p=0.002)$, and lower vitamins B1, B2, C, $\mathrm{Zn}$ and calcium than those in the control group.

\section{Discussion}

In this age and sex-matched case-control study, we compared nutrient intake, dietary patterns, and anthropometric variables of children with ADHD in comparison to healthy controls. The main findings of this study were lower levels of protein intake, higher poor dietary habits (e.g., consumption of ready-to-eat food), and lower levels of micronutrient intake such as vitamin $C$, vitamin B1, vitamin B2, calcium, zinc, and iron in children with ADHD compared to typically-developing peers. ADHD children had greater BMI values as well.

With regard to nutrient intake and dietary patterns, although there was no significant difference in total intake of carbohydrates and fat between the groups, consumption of simple sugars and tea was significantly higher and protein intake was significantly lower in children with ADHD. In the study by Ríos-Hernández et al. (2017), (mean age: $9.3 \pm 2.8$ years; $56.7 \%$ boys) there was no significant difference in dietary caloric intake and consumption of carbohydrate and fat between children with ADHD and normal children [21]. However, the level of simple sugars and caffeine consumption in children with ADHD was significantly higher. They also found that children with ADHD received less protein than healthy controls. It should be noted that although in their study consumption of micronutrients such as iron and zinc in the ADHD group was lower than the children in the control group, this difference was not statistically significant [21]. Furthermore, in a study by Azad Bakht et al. (2012) was found that in children with ADHD (mean age: $7 \pm 2$ years; $71 \%$ boys), carbohydrate intake is more than normal children. Also, vitamin C, vitamin B1, vitamin B2, calcium, zinc, and iron intakes in children with ADHD were significantly lower than healthy children; this finding is in line with our results [22]. Another relevant study in children with ADHD (mean age: $8.42 \pm 1.72$ years; $83.8 \%$ boys) found a series of negative correlations between ADHD symptoms and seafood and meat consumption $(p=0.006)$, dietary intake of zinc, protein, phosphorus, selenium, calcium, and riboflavin

Table 3 Comparison of cronutrients as well as some dietary habits in case and control groups

\begin{tabular}{|c|c|c|c|}
\hline Food & Case group & Control group & $P$-value \\
\hline Carbohydrate (energy percentage) & $60.48 \pm 3.05$ & $59.86 \pm 2.71$ & NS \\
\hline Fat (energy percentage) & $29.03 \pm 3.33$ & $28.5 \pm 2.15$ & NS \\
\hline Protein (energy percentage) & $10.49 \pm 2.47$ & $11.64 \pm 2.12$ & $0.001 *$ \\
\hline Simple sugars (g) & $44.66 \pm 7.41$ & $41.3 \pm 8.93$ & $0.007 *$ \\
\hline Tea (glasses) & $2.4 \pm 0.9$ & $1.9 \pm 0.5$ & $0.006 *$ \\
\hline Ready-made meal (weekly turn) & $1.44 \pm 0.72$ & $0.83 \pm 0.61$ & $0.002 *$ \\
\hline Vitamin A (mg) & $512.1 \pm 100.1$ & $524.23 \pm 98.7$ & NS \\
\hline Vitamin E (mg) & $7.4 \pm 2.5$ & $7.8 \pm 1.9$ & NS \\
\hline Vitamin B1 (mg) & $0.82 \pm 0.17$ & $0.94 \pm 0.18$ & $0.001 *$ \\
\hline Vitamin B2 (mg) & $0.47 \pm 0.1$ & $0.51 \pm 0.09$ & $0.004 *$ \\
\hline Vitamin B3 (mg) & $14.53 \pm 8.1$ & $14.8 \pm 8.3$ & NS \\
\hline Vitamin B5 (mg) & $2.1 \pm 0.82$ & $2.2 \pm 0.91$ & NS \\
\hline Vitamin B6 (mg) & $0.92 \pm 0.68$ & $1.01 \pm 0.73$ & NS \\
\hline Vitamin B12 (mg) & $2.1 \pm 1.15$ & $2.2 \pm 1.12$ & NS \\
\hline Vitamin C (mg) & $82.43 \pm 17.51$ & $92.26 \pm 17.52$ & $0.001 *$ \\
\hline Iron (mg) & $9.32 \pm 1.1$ & $9.6 \pm 0.99$ & NS \\
\hline Selenium (micrograms) & $24.05 \pm 9.6$ & $25.19 \pm 13.8$ & NS \\
\hline Zinc (mg) & $2.91 \pm 0.55$ & $3.06 \pm 0.51$ & $0.044^{*}$ \\
\hline Calcium (mg) & $769.9 \pm 121.03$ & $803.82 \pm 96.73$ & $0.030^{*}$ \\
\hline Magnesium (mg) & $82.05 \pm 26.34$ & $85.18 \pm 25.09$ & NS \\
\hline
\end{tabular}

* T-test is statistically significant at $p<0.5$ 

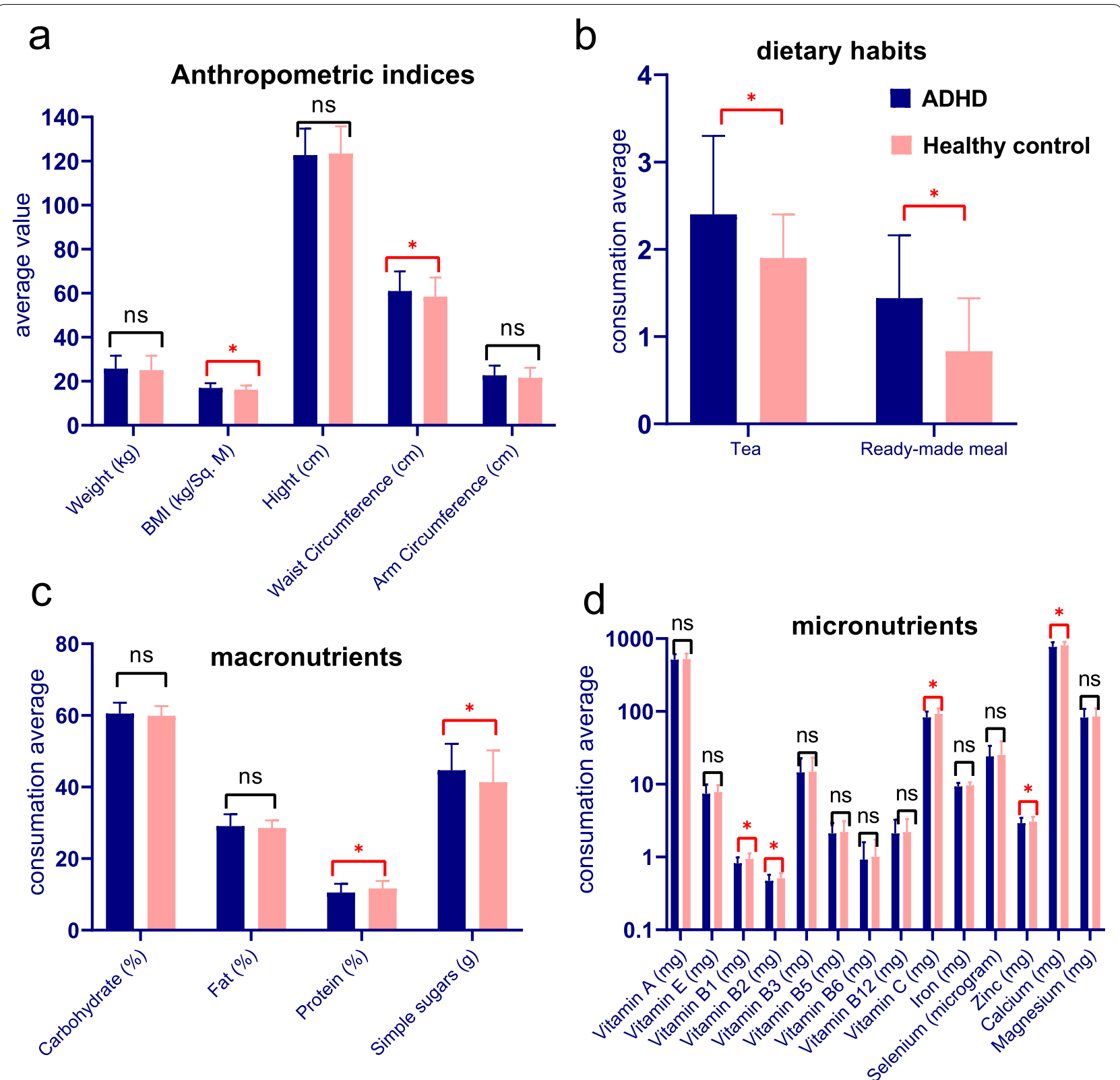

Fig. 1 The mean values of anthropometric variables (a), dietary habits (b), macronutrients (c) and micronutrients (d) in ADHD children compared to healthy controls. Error bars represent standard deviation. ns = nonsignificant; asterisk = significant difference between groups

( $p=0.014)$, and the serum zinc level was negatively associated to $\operatorname{ADHD}(p=0.003)$ [23].

In anthropometric indices, a non-significant difference was found between the arm circumference of ADHD children and normal children [24]. Another cohort study found that ADHD is not recognized a risk factor for significant weight gain from its normal level [25]. In our study, however, the arm circumference of children with ADHD was lower than normal children but this difference was not statistically significant. Different dietary patterns and socio-demographic or genetic factors may explain our novel results. In our study, in the ADHD group weight was slightly greater and height was slightly shorter compared to the control group. This was why the BMI was significantly greater in the ADHD group. Also, the abdominal circumference was significantly higher in the ADHD group. In line with our results, another study showed that the abdominal circumference and body fat percentage of non-medicated boys with ADHD was higher but the height was shorter than normal peers [13]. 
Along with what we found in the present study, the mean height of ADHD children was shorter compared to the control group in the study performed by Ríos Hernández et al. (2017) $(136.5 \pm 16.8 \mathrm{~cm}$ vs. $138.6 \pm 17.3 \mathrm{~cm}$, respectively). Also, the mean weight of children in the case group (ADHD) in their study was higher than the control group $(38.1 \pm 16.2 \mathrm{~kg}$ vs. $36.4 \pm 14.5 \mathrm{~kg}$; respectively) and there were no statistically significant differences between the two groups in these regards [21].

When it comes to height, results are also mixed. A study found that the height of non-medicated children with ADHD was significantly higher than normal children but after the beginning of pharmacotherapy, the growth velocity reduced so that those who remained on stimulant medication showed an annual growth rate about $20 \%$ less than what expected [26]. Moreover, in the two separate studies conducted by Ptacek et al. group, short height for age and sex was observed in non-medicated children with ADHD [13, 14]. In the present study, although the height of children with ADHD was slightly lower than the control group, however, the difference was not significant even after controlling for the impact of ADHD subtype and disorder severity. There is no significant difference in height at an earlier age compared to normal peers, however, over time, due to the growth retardation, the height of ADHD children remains shorter than normal children.

In this line, there is still controversy in various studies over the BMI difference between children with ADHD and their normal peers. In a relevant study, the BMI of children with ADHD was $19.6 \pm 3.4$ while it was $18 \pm 3.3$ in normal peers. Statistical analysis indicated that this difference was statistically significant [21]. Contrary to the above, the Mustillo et al. (2003) indicated no significant difference in BMI between children with ADHD and normal children [25]. In our study, in line with most studies, children with ADHD were more likely to have upper BMI than normal children. With respect to waist circumference, a study showed that children with ADHD who received no medication had significantly higher waist circumference than normal children [13]. On the other hand, the same researcher showed a significant difference in growth between children with ADHD that did not receive any medications and normal children when the sample size was doubled [14]. The synthesis of the results of this work by the researcher reveals that the involvement of some anthropometric indices, and reduction in growth velocity in children with ADHD, can be one of the clinical manifestations of the disease itself and not due to the complications of medications. ADHD children have low self-control so they show less food abstinence when it comes to food. Especially in the consumption of fast food and high in sugar. This reduces their balance, weight, and height.
Finally, we observed differences in eating behavior between ADHD children and healthy controls. Children with ADHD had a significantly higher waist circumference which is an indicator of fat tissue accumulation in the abdomen. Weight gain and fat accumulation in ADHD may be due to the association between impulsive behavior and loss of control in eating behaviors [27]. Furthermore, it is known that aggression and lack of attention in these children increase their appetite for food [28]. Besides, improper food patterns lead to an increase in body weight. According to the studies performed on food patterns in children with ADHD, the results indicated a high consumption of simple sugars, ready-made meals and a high-carbohydrate diet [29]. Due to the low levels of dopamine neurotransmitters, serotonin, and norepinephrine in the brain that lead to mood disorders and reduced desire to engage in physical activity, these children and adolescents are prone to overweight and obesity [30]. In children with ADHD, moving skills, executive functioning, and physical fitness are significantly lower compared to normal children who may contribute to obesity [31]. Overall, the results of this study indicate that there is a need to intervene in the lifestyle and eating behavior of children with ADHD. One interesting point here is the potential link between poor nutritional behavior and sleep problems in ADHD. It is known that there is an association between micronutrient status including some of those that ADHD children had lower levels (e.g., Zink, magnesium, iron) and sleep patterns [32]. On the other hand, ADHD comes with sleep difficulties and circadian problems [33] which are easily affected by lifestyle changes including the pandemic situation [34, 35]. Life style interventions should thus include not only eating behavior but other related factors such as sleep pattern.

Some limitations should be considered in our study. Despite the instructions and guidelines delivered to parents, studied food pattern may have missed some items, including snacks used in schools, which may children provide from school buffet. Other limitations of this study include the small sample size. Furthermore, parents' awareness of ADHD may affect the children's dietary patterns. It is suggested that Martin's anthropometric measuring instruments be used for weight measurement in future research.

\section{Conclusion}

Children with ADHD have higher waist circumference and BMI than healthy children, and this difference is related to the severity of the disease and its type. The BMI and waist circumference in children with mild ADHD and mostly attention-deficit type was significantly higher than the control group. Children with ADHD consume more simple sugars, tea, and ready-made foods but lower 
protein, vitamin $\mathrm{B} 1$, vitamin $\mathrm{B} 2$, vitamin $\mathrm{C}$, zinc and calcium compared with their normal control peers. These results suggest lifestyle and nutritional interventions in children with ADHD as early as possible.

\author{
Abbreviations \\ ADHD: Attention-deficit and Hyperactivity Disorder; FFQ: Food Frequently \\ Questionnaires; BMI: Body Massive Index; DSM-5: Diagnostic and Statistical \\ Manual of Mental Disorders.
}

\section{Acknowledgments}

The researchers appreciate all parents and children who participated in this study, as well as to the Fatemi Hospital, Child Psychiatry division., who are fully committed to this study.

\section{Authors' contributions}

PM \& MN conceived the study. HS \& MN collected the data and interpreted the data. MN and MAS wrote the first draft. MAS, SAM \& RR revised and reviewed. All authors read and approved the final manuscript.

\section{Funding}

This research didn't receive any grant from any funding agency in the public, commercial or not-for-profit sectors.

\section{Availability of data and materials}

The datasets used and/or analyzed during the current study are available from the corresponding author on reasonable request.

\section{Declarations}

\section{Ethics approval and consent to participate}

The protocol was conducted in accordance with the latest version of the Declaration of Helsinki and was approved by the Institutional Review Board and ethical committee at the Aradabil University of Medical Sciences. We obtained the written informed consent form the parents and oral assent from children before participation in the study. The ethical approval was obtained from the ethics committee review board in the Ardabil University of Medical Sciences (ethics code: IR.ARUMS.REC.1395.81).

\section{Consent for publication}

All participants' parents were instructed about experimental procedures and gave their written informed consent.

\section{Competing interests}

Mohammad Ali Salehinejad is a member of the Scientific Advisory Board of Neuroelectrics. All other authors declare no competing interests.

\section{Author details}

'Department of Psychiatry, Fatemi Hospital, School of Medicine, Ardabil University of Medical Sciences, Ardabil, Iran. ${ }^{2}$ Department of Psychiatry, Tehran University of Medical Sciences, Tehran, Iran. ${ }^{3}$ Department of Psychology, University of Tehran, Tehran, Iran. ${ }^{4}$ Department of Psychology and Neurosciences, Leibniz Research Centre for Working Environment and Human Factors, Dortmund, Germany.

Received: 6 April 2021 Accepted: 12 January 2022

Published online: 29 January 2022

\section{References}

1. Mohammadi MR, Ahmadi N, Khaleghi A, Mostafavi SA, Kamali K, Rahgozar $\mathrm{M}$, et al. Prevalence and correlates of psychiatric disorders in a national survey of Iranian children and adolescents. Iran J Psychiatry. 2019;14(1):1.

2. American Psychiatric Association: Diagnostic and statistical manual of mental disorders (5th ed). Arlington: American Psychiatric Pub; 2013.
3. Doernberg E, Hollander E. Neurodevelopmental Disorders (ASD and ADHD): DSM-5, ICD-10, and ICD-11. CNS spectrums. 2016;21(4):295-9. https://doi.org/10.1017/S1092852916000262.

4. Molavi P, Nadermohammadi M, Ghojehbeiglou HS, Vicario CM, Nitsche MA, Salehinejad MA. Cognitive correlates of ADHD subtypes and its association with self-esteem: A quantitative difference. BMC Psychiatry. 2020. https://doi.org/10.1186/s12888-020-02887-4.

5. Salehinejad MA, Ghanavati E, Rashid MHR, Nitsche MA. Hot and cold executive functions in the brain: A prefrontal-cingular network. Brain Neurosci Adv. 2021:5239821282110077. https://doi.org/10.1177/23982 128211007769

6. Mohammadi MR, Mostafavi SA, Hooshyari Z, Khaleghi A, Ahmadi N, Molavi P, et al. Prevalence, correlates and comorbidities of feeding and eating disorders in a nationally representative sample of Iranian children and adolescents. Int J Eat Disord. 2019. https://doi.org/10.1002/eat.23197.

7. Molavi P, Mikaeili N, Ghaseminejad MA, Kazemi Z, Pourdonya M. Social anxiety and benign and toxic online self-disclosures: an investigation into the role of rejection sensitivity, self-regulation, and internet addiction in college students. J Nerv Ment Dis. 2018;206(8):598-605. https://doi.org/ 10.1097/nmd.0000000000000855.

8. Mostafavi S-A, Mohammadi MR, Hosseinzadeh P, Eshraghian MR, Akhondzadeh S, Hosseinzadeh-Attar MJ, et al. Dietary intake, growth and development of children with ADHD in a randomized clinical trial of Ritalin and Melatonin co-administration: Through circadian cycle modification or appetite enhancement? Iran J Psychiatry. 2012;7(3):114.

9. Holton KF, Nigg JT. The Association of Lifestyle Factors and ADHD in Children. J Atten Disord. 2016;0(0):1087054716646452. https://doi.org/10. 1177/1087054716646452.

10. Nigg JT, Holton K. Restriction and Elimination Diets in ADHD Treatment. Child Adolesc Psychiatr Clin N Am. 2014;23(4):937-53. https://doi.org/10. 1016/j.chc.2014.05.010.

11. Utkualp N, Ercan I. Anthropometric measurements usage in medical sciences. BioMed Res Int. 2015;2015. https://doi.org/10.1155/2015/404261.

12. Shils ME, Shike M. Modern nutrition in health and disease: Lippincott Williams \& Wilkins; 2006

13. Ptacek R, Kuzelova H, Paclt I, Zukov I, Fischer S. Anthropometric changes in non-medicated ADHD boys. Neuro Endocrinol Lett. 2009;30(3):377-81 https://www.researchgate.net/publication/38034789.

14. Ptáček R, Kuželová H, Paclt I, Žukov I, Fischer S. Somatic and endocrinological changes in non medicated ADHD children. Prague Med Rep. 2009;110(1):25-34.

15. Amani R, Khajeh Mougahi N. Comparison between nutritional pattern of school children with attention deficit hyperactivity disorder and that of normal subjects. Razi J Med Sci. 2005;12(45):37-42 URL: http://rjms.iums. ac.ir/article-1-428-en.html.

16. Güngör S, Celiloğlu ÖS, Raif SG, Özcan ÖÖ, Selimoğlu MA. Malnutrition and obesity in children with ADHD. J Atten Disord. 2016;20(8):647-52. https://doi.org/10.1177/1087054713478465.

17. Fliers EA, Buitelaar JK, Maras A, Bul K, Höhle E, Faraone SV, et al. ADHD is a risk factor for overweight and obesity in children. J Dev Behav Pediatr. 2013;34(8). https://doi.org/10.1097/DBP.0b013e3182a50a67.

18. Yang R, Mao S, Zhang S, Li R, Zhao Z. Prevalence of obesity and overweight among Chinese children with attention deficit hyperactivity disorder: a survey in Zhejiang Province, China. BMC Psychiatry. 2013;13(1):133. https://doi.org/10.1186/1471-244X-13-133.

19. Conners CK, Sitarenios G, Parker JDA, Epstein JN. The Revised Conners' Parent Rating Scale (CPRS-R): factor structure, reliability, and criterion validity. J Abnorm Child Psychol. 1998;26(4):257-68. https://doi.org/10. 1023/A:1022602400621.

20. Cade J, Thompson R, Burley V, Warm D. Development, validation and utilisation of food-frequency questionnaires-a review. Public Health Nutr. 2002;5(4):567-87. https://doi.org/10.1079/PHN2001318.

21. Ríos-Hernández A, Alda JA, Farran-Codina A, Ferreira-García E, IzquierdoPulido M: The Mediterranean diet and ADHD in children and adolescents. Pediatrics 2017, 139(2):e20162027. https://doi.org/10.1542/peds. 2016-2027.

22. Azadbakht L, Esmaillzadeh A. Dietary patterns and attention deficit hyperactivity disorder among Iranian children. Nutrition. 2012;28(3):2429. https://doi.org/10.1542/peds.2016-2027. 
23. Zhou F, Wu F, Zou S, Chen Y, Feng C, Fan G. Dietary, nutrient patterns and blood essential elements in Chinese children with ADHD. Nutrients. 2016:8(6):352. https://doi.org/10.3390/nu8060352.

24. Ptacek R, Kuzelova H, Paclt I, Zukov I, Fischer S. ADHD and growth: anthropometric changes in medicated and non-medicated ADHD boys. Med Sci Monit. 2009;15(12):CR595-9.

25. Mustillo S, Worthman C, Erkanli A, Keeler G, Angold A, Costello EJ. Obesity and psychiatric disorder: developmental trajectories. Pediatrics. 2003:111(4):851-9. https://doi.org/10.1542/peds.111.4.851.

26. Swanson J, Greenhill L, Wigal T, Kollins S, Stehli A, Davies M, et al. Stimulant-related reductions of growth rates in the PATS. J Am Acad Child Adolesc Psychiatry. 2006;45(11):1304-13. https://doi.org/10.1097/01.chi. $0000235075.25038 .5 \mathrm{a}$

27. Mikami AY, Hinshaw SP, Patterson KA, Lee JC. Eating pathology among adolescent girls with attention-deficit/hyperactivity disorder. J Abnorm Psychol. 2008;117(1):225. https://doi.org/10.1037/0021-843X.117.1.225.

28. Bazar KA, Yun AJ, Lee PY, Daniel SM, Doux JD. Obesity and ADHD may represent different manifestations of a common environmental oversampling syndrome: a model for revealing mechanistic overlap among cognitive, metabolic, and inflammatory disorders. Med Hypotheses. 2006;66(2):263-9. https://doi.org/10.1016/j.mehy.2005.02.042.

29. Cortese S, Angriman M, Maffeis C, Isnard P, Konofal E, Lecendreux M, et al. Attention-deficit/hyperactivity disorder (ADHD) and obesity: a systematic review of the literature. Crit Rev Food Sci Nutr. 2008;48(6):524-37. https:// doi.org/10.1080/10408390701540124

30. Davis C, Levitan RD, Kaplan AS, Carter J, Reid C, Curtis C, et al. Reward sensitivity and the D2 dopamine receptor gene: a case-control study of binge eating disorder. Prog Neuro-Psychopharmacol Biol Psychiatry. 2008;32(3):620-8. https://doi.org/10.1016/j.pnpbp.2007.09.024.

31. Pan C-Y, Chang Y-K, Tsai C-L, Chu C-H, Cheng Y-W, Sung M-C. Effects of physical activity intervention on motor proficiency and physical fitness in children with ADHD: An exploratory study. J Atten Disord. 2017;21(9):783-95. https://doi.org/10.1177/1087054714533192.

32. Ji X, Grandner MA, Liu J. The relationship between micronutrient status and sleep patterns: a systematic review. Public Health Nutr. 2017:20(4):687-701. https://doi.org/10.1017/S1368980016002603.

33. Bondopadhyay U, Diaz-Orueta U, Coogan AN. A Systematic Review of Sleep and Circadian Rhythms in Children with Attention Deficit Hyperactivity Disorder. J Atten Disord. 2022;26(2):149-224. https://doi.org/10. 1177/1087054720978556.

34. Çetin FH, Uçar HN, Türkoğlu S, Kahraman EM, Kuz M, Güleç A. Chronotypes and trauma reactions in children with ADHD in home confinement of COVID-19: full mediation effect of sleep problems. Chronobiol Int. 2020;37(8):1214-22. https://doi.org/10.1080/07420528.2020.1785487.

35. Salehinejad MA, Azarkolah A, Ghanavati E, Nitsche MA. Circadian disturbances sleep difficulties and the COVID-19 pandemic. Sleep Med. 2021. https://doi.org/10.1016/j.sleep.2021.07.011.

\section{Publisher's Note}

Springer Nature remains neutral with regard to jurisdictional claims in published maps and institutional affiliations.

Ready to submit your research? Choose BMC and benefit from:

- fast, convenient online submission

- thorough peer review by experienced researchers in your field

- rapid publication on acceptance

- support for research data, including large and complex data types

- gold Open Access which fosters wider collaboration and increased citations

- maximum visibility for your research: over $100 \mathrm{M}$ website views per year

At BMC, research is always in progress.

Learn more biomedcentral.com/submissions 